\title{
Antimicrobial Effect for Both of Carboxy Methyl Cellulose and Chitosan Treated with Ferulic Acid or Nanosilver Particles as Edible Coatings used for Some Refrigerated Beef Samples El-Refai, A. A. ${ }^{1}$; A. M. Hassan ${ }^{1}$; Kh. Nagy ${ }^{2}$ and M. M. Rabie ${ }^{1}$ \\ ${ }^{1}$ Food Industries Dept., Faculty of Agriculture, Mansoura University, Mansoura, Egypt. \\ ${ }^{2}$ Food Technology Research Institute. Agricultural Research Center. Giza, Egypt.
}

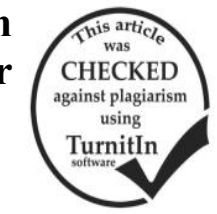

\section{ABSTRACT}

Two edible coatings namely carboxy methyl cellulose (CMC) and chitosan were examined as edible coatings either alone or with addition of ferulic acid or silver nanoparticles for some refrigerated beef samples. During 12 days experiment, the microbiological quality was carried out by examining some spoilage and pathogenic bacteria. The examined bacteria were total viable count, salmonella and shigella, Staphylococcus spp. plus molds and yeasts. Obtained results showed that using of chitosan has better effect than $\mathrm{CMC}$ as an edible coating of meat. In addition, results showed that addition of ferulic acid to either CMC or to chitosan increased the reduction percent of all examined bacteria, and moreover, the use of silver nanoparticles with either $\mathrm{CMC}$ or chitosan increased the removing percent of examined bacteria. This results indicated that addition of silver nanoparticles was more efficient in removing of viable bacteria than ferulic acid with chitosan than that of CMC.

Keywords: CMC, chitosan, ferulic acid, silver nanoparticles, salmonella and shigella, Staphylococcus spp. molds and yeasts and meat.

\section{INTRODUCTION}

Edible Coatings act as barrier between food and the surrounding environment to improve the quality of food products protecting them from physical, chemical, and biological deterioration. Edible films and coatings offer some benefits such as edibility, biocompatibility, aesthetic appearance, barrier properties, Being nontoxic, non-polluting and having low cost (Han, 2000). Also, coatings and biofilms, by themselves or acting as carriers of foods additives (i.e.: antioxidants, antimicrobials), have been principally considered in food preservation because of their facility to extend the shelf life (Franssen and Krochta 2003)

Antimicrobial or antioxidant compounds integrated into the polymer matrix may inhibit growth of spoilage and pathogenic microbes, interval of meat fat rancidity, discoloration prevention, and even improvement of the nutritional quality of coated foods Soliva-Fortuny, R. et al. (2012). Meanwhile, Darmadji and Izumimoto, (1994) reported that higher concentrations $(0.1 \%)$ were required to inhibit E.coli growth.

Among noble-metal nanomaterial's, silver nanoparticles (SNPs) have received considerable attentions owed to their attractive antimicrobial properties (Rai et al., 2009).

Silver compounds have been used to treat burns, wounds and infections. Various salts of silver and their derivatives are used as antimicrobial agents (Ip et al, 2006). Contemporary studies have informed that nanosized silver particles reveal antimicrobial properties (Petica et al. 2008, Rai et al. 2009). Nanoparticles of silver have been studied as a medium for antibiotic delivery, and to synthesize composites for use as disinfecting filters and coating ingredients (Kim et al. 2007, Ruparelia et al. 2006). Accordingly, this study was conducted to investigate the ability of using two kinds of edible coating namely carboxy methyl cellulose and chitosan without additive or incorporated with ferulic acid or silver nanoparticles against some spoilage and pathogenic microbes.

\section{MATERIALS AND METHODS}

Materials:

Carboxy methyl cellulose with an average molecular weight of $41.000 \mathrm{~g}$, medium viscosity 400$800 \mathrm{cp}$ (practical grade), and glycerol were obtained from El-Gomhouria Company, Cairo, Egypt. Chitosan extracted from crab shells was obtained from Roth, Germany. Starch was purchased from Pio Chem Cairo, Egypt, acetic acid glacial (100\%), from Tedia Company, USA. Ferulic acid (95\%) was purchased from Sigma Company. Nanosilver particle was purchased from Bavaria Company, Germany.

Malt extract media was obtained from Qualikems Company, India, MacConkey agar No.3 and Plate Count Agar were purchased from LAB M Limited, United Kingdom. Agar S. S. was obtained from BioCen, Cuba. Baired parker agar base was purchased from Titan media Company, India.

Beef samples:

Beef sirloin retail cuts were obtained from a private shop in a local market in Mansoura city immediately after slaughtering. Then transferred in an ice box to the laboratory.

\section{Methods:}

Treatment was applied except the control sample (T1) as uncoated, samples were coated with CMC edible coating, $\mathrm{CMC}+$ Ferulic acid and $\mathrm{CMC}+$ nanosilver particles, respectively, as T2, T3 and T4.chitosan as edible coating used for the rest of samples, chitosan + ferulic acid and chitosan + nanosilver particles as T5,T6 and $\mathrm{T} 7$ respectively. All samples were refrigerated at $4 \pm 1{ }^{\circ} \mathrm{C}$, The microbial pollution on the treated samples was determined at zero time and every $96 \mathrm{hrs}$.

Preparation of CMC coatings solutions:

With an average molecular weight of $41.000 \mathrm{~g} / \mathrm{mol}$, medium viscosity of $400-800 \mathrm{cp}$ and glycerol as plastizer ,CMC (1g) was dissolved in $100 \mathrm{ml}$ distilled water, glycerol was added $(1 \mathrm{ml})$ and solution was stirred for another 15 min.Ferulic acid was added at concentration of 100 p.p.m to coating solution. Nanosilver particles $40 \mathrm{~nm}$ 
at concentration of 50 p.p.m (Bavaria Company Germany) was added to coating solution.

\section{Preparation of chitosan coating solutions}

Chitosan $(1 \% \mathrm{w} / \mathrm{w})$ was dispersed in $2 \%(\mathrm{w} / \mathrm{w})$ acetic acid glacial solution under gentle stirring. Starch $1 \%$ was added. Glycerol as plastizer was added at a concentration of $1 \%(\mathrm{w} / \mathrm{w})$ María B. Vásconezet et al, (2009). Ferulic acid was added at concentration of 100 p.p.m to coating solution. Silver nanoparticles $(40 \mathrm{~nm})$ at concentration of 50 p.p.m was added to coating solution.

\section{Microbiological examination:}

Sample preparation.

Ten grams of each sample were added to $90 \mathrm{ml}$ of saline solution and mixed thoroughly to give 1/10 dilution. Serial dilutions were prepared to be used for microbiological examination using different cultivation media.

\section{Total bacterial count:}

The total bacterial counts were determined using the plate counts technique on a nutrient agar medium according to the procedures described in Merck, (2000). The plates were incubated at $37^{\circ} \mathrm{C}$ for $48 \mathrm{hrs}$.

\section{Spore- forming mesophilic bacterial count:}

The previous dilutions were heated to $85^{\circ} \mathrm{C}$ for 15 min before being plated on the same previous medium for aerobic bacterial counts (tryptone glucose yeast extract agar). Plates were incubated at $37^{\circ} \mathrm{C}$ for 24 and $48 \mathrm{~h}$ according to the method described in Merck, (2000).

\section{Psychrophilic bacterial count:}

Psychrophilic bacterial count was carried out as described in typical procedure of the total plate bacterial count methods, except, incubation was achieved at $8^{\circ} \mathrm{C}$ for 5 days according to Merck, (2000).

\section{Coliform bacterial count:}

The coliform bacteria were detected using McConkey agar medium according to the procedures described in Merck, (2000). The plates were incubated at $37^{\circ} \mathrm{C}$ for $24 \mathrm{hrs}$.

\section{Detection of Salmonella and Shigella:}

The presence or absence of Salmonella and Shigella was detected according to the methods described by FAO, (2013).

\section{Staphylococcus spp. count:}

Staphylococcus spp. were detected according to the method described in Merck, (2000). Using $5 \mathrm{ml}$ of egg yolk tellurite emulsion to each $100 \mathrm{ml}$ of sterilized medium which mixed well before pouring in the plates. The plates were incubated at $37^{\circ} \mathrm{C}$ for 24 or $48 \mathrm{hr}$.

\section{Yeasts and molds:}

The procedures of Merck, (2000) were followed for the examination of yeast and mold counts using potato-dextrose agar medium. The plates were incubated at $28^{\circ} \mathrm{C}$ for 5 days. When excessive growth develops, colonies counted after 3 days and reported as yeasts and molds count per gram of examined sample.

\section{RESULTS AND DISCUSSION}

Results in Tab. 1 showing decrease in the total viable bacterial count in a percent of $38.56,2.69$ and 23.31 in case of $\mathrm{T} 1$ (control) the examined sample without coating after 4,8 and 12 days of refrigeration periods, respectively.

In case of using CMC alone (T2), the count of total viable bacterial count decreased from $223 \mathrm{cfu} \times 103 / \mathrm{g}$ to 92 $\mathrm{cfu} \times 103 / \mathrm{g}$ of examined sample in a percent of 58.74 while this percent was 5.38 and 50.67 after 8 and 12 days, respectively. This decreasing percent became lower when using CMC (T3) with ferulic acid to be $67 \mathrm{cfu} \times 103 / \mathrm{g}, 219$ and $103 \mathrm{cfu} \times 103 / \mathrm{g}$ of examined sample expressed in 69.95, 1.79 and $53.81 \%$, respectively.

Tab. 1. Effect of treated CMC and Chitosan edible coatings with or without ferulic acid or nanosilver particles on total viable bacterial count on some refrigerated beef sample:

Total viable bacterial count, $\mathrm{cfu} \times 10^{3} / \mathrm{g}$ examined sample

\begin{tabular}{lcccc}
$\begin{array}{l}\text { Refrigeration } \\
\text { period (day) } \\
\text { Treatment (T) }\end{array}$ & $\mathbf{0}$ & $\mathbf{4}$ & $\mathbf{8}$ & $\mathbf{1 2}$ \\
\hline T1 & 223 & 137 & 217 & 171 \\
T2 & 223 & 92 & 211 & 110 \\
T3 & 223 & 67 & 219 & 103 \\
T4 & 223 & 58 & 169 & 70 \\
T5 & 223 & 28 & 130 & 13 \\
T6 & 223 & 27 & 122 & N.D \\
T7 & 223 & N.D & 72 & N.D \\
\hline T1: uncoated & \multicolumn{5}{c}{ T2: CMC } \\
T3: CMC + Ferulic acid & T4: CMC + Nanosilver particles \\
T5: Chitosan & \multicolumn{5}{c}{ T6: Chitosan + Ferulic acid } \\
T7: Chitosan + Nanosilver particles N.D.: Not Detectable
\end{tabular}

Results of T4 of CMC with silver nanoparticles, the decreasing percent became 73.99, 24.21 and 68.60 $\%$ after 4,8 and 12 days, respectively.

These results indicated that using of the silver nanoparticles achieved superiority of bacterial decreasing than ferulic acid with CMC since the decreasing percent were 69.95 and $53.81 \%$ in case of ferulic acid while these percent were 73.99 and $68.60 \%$ in case of silver nanoparticles after 4 and 12 days.

Results of chitosan (T5), showing that after 4 days of refrigeration the total viable bacterial count decreased by $87.44 \%$ while $41.70 \%$ was found after 8 days. After 12 days of refrigeration, the decreasing percent was $94.17 \%$ in case of using chitosan alone. These percent were $87.89 \%, 45.29 \%$ after 4 and 8 days, respectively, when using silver nanoparticles the decrease percent was $67.71 \%$ after 8 days of refrigeration. Not detectable results were noticed in case of using ferulic (T6) acid after 12 days and when using silver nanoparticles (T7) after 4 and 12 days. Again, this means that silver nanoparticles was more efficient in removing viable bacteria than ferulic acid with chitosan.

Sharifi, et al. (2012) showed that Ag-Nps have antimicrobial activity and it also have a great effect on total bacterial count reduction as a new generation of antimicrobial. Shahverdi, et al. (2007) reported that silver nanoparticles has an antibacterial activity against Gram-positive and Gram-negative bacteria.

Concerning storage for 8 days, the microorganisms count was increased. This increase was not reasonable. 
Detection of spore forming bacteria:

Examining spore forming bacteria, Tab. 2 showed that using of CMC (T1) as an edible coating decreased their count from $182 \mathrm{cfu} \times 10^{3} / \mathrm{g}$ to $123 \mathrm{cfu}$ $\times 10^{3} / \mathrm{g}$ of examined sample (T2) in percent of $32.41 \%$ after 8 days of refrigeration. This decrease percent was $54.87 \%$ after 12 days.

Tab. 2. Effect of treated CMC and Chitosan edible coatings with or without ferulic acid or nanosilver particles on Spore forming bacteria on some refrigerated beef sample:

\begin{tabular}{lcccc}
\hline & $\begin{array}{c}\text { Spore forming bacteria , } \mathbf{c f u} \times \mathbf{1 0}^{\mathbf{3}} / \mathbf{g} \\
\text { examined sample }\end{array}$ \\
$\begin{array}{l}\text { Refrigeration } \\
\text { period(day) } \\
\text { Treatment (T) }\end{array}$ & $\mathbf{0}$ & $\mathbf{4}$ & $\mathbf{8}$ & $\mathbf{1 2}$ \\
\hline T1 & 97 & 30 & 182 & 109 \\
T2 & 97 & 31 & 123 & 59 \\
T3 & 97 & 9 & 141 & 35 \\
T4 & 97 & 5 & 8 & 12 \\
T5 & 97 & 2 & 7 & N.D \\
T6 & 97 & N.D & 3 & N.D \\
T7 & 97 & N.D & N.D & N.D \\
\hline
\end{tabular}

T1- T7 see Tab. 1

The removing power of spore forming bacteria was increased by adding ferulic acid and silver nanoparticles to be $90.72,94.84 \%$ and $63.91,87.62 \%$ after 4 and 12 days, respectively.

The bacterial removing was also increased when using chitosan either alone (T5) or after adding ferulic acid (T6) or silver nanoparticles (T7) as shown as in Tab. 2. Results showed that chitosan decreased the count of spore formers from $97 \mathrm{cfu} \times 10^{3} / \mathrm{g}$ to $2.0 \mathrm{cfu}$ $\times 10^{3} / \mathrm{g}$ of examined sample $(97.93 \%)$ and to $7.0 \mathrm{cfu}$ $\times 10^{3} / \mathrm{g}$ of examined sample $(92.78 \%)$ after 4 and 8 days of refrigeration, respectively.

Not detectable results was found after 12 days of refrigeration. In case of addition of ferulic to chitosan , the removing of spore formers is increased to be N.D. , $3.0 \mathrm{cfu} \times 10^{3} / \mathrm{g}$ of examined sample and not detectable after 4,8 and 12 days of refrigeration, respectively.

The efficient of bacterial removal was also increased when using silver nanoparticles with chitosan being not detectable numbers in the three examined times 4,8 and 12 . This means that the silver nanoparticles was more efficient than ferulic acid in bacterial removal.

Dave and Ghaly (2011) reported that pathogenic microbes do not survive through meat cooking but several of their toxins and spores do.

Detection of coliform bacteria:

For coliform bacteria, results in Tab. 3 showed that both $\mathrm{CMC}$ and chitosan are good edible coating either alone or with addition of ferulic acid or silver nanoparticles. In case of using CMC alone (T2) the removing of coliform bacteria were $66.4,84.8$ and 30.4 $\%$ after 4,8 and 12 days, respectively. These percent were $84,87.2$ and $83.2 \%$ when using CMC with silver nanoparticles (T4) after 4, 8 and 12 days, respectively.
Tab. 3. Effect of treated CMC and Chitosan edible coatings with or without Ferulic acid or Nanosilver particles on coliform bacteria on some refrigerated beef sample:

Coliform bacteria cfu $\times 10^{3} / \mathrm{g}$ examined sample

\begin{tabular}{lcccc}
$\begin{array}{l}\text { Refrigeration } \\
\text { period (day) } \\
\text { Treatment (T) }\end{array}$ & $\mathbf{0}$ & $\mathbf{4}$ & $\mathbf{8}$ & $\mathbf{1 2}$ \\
\hline T1 & 125 & 105 & 27 & 154 \\
T2 & 125 & 42 & 19 & 87 \\
T3 & 125 & 23 & 17 & 28 \\
T4 & 125 & 20 & 16 & 21 \\
T5 & 125 & 11 & 15 & 24 \\
T6 & 125 & 7 & 11 & 9 \\
T7 & 125 & 6 & 8 & 2 \\
\hline T1- T7 see Tab.1 & & & &
\end{tabular}

The same trend of obtained results was found in case of using chitosan. The reduction percent of coliform bacteria were 91.2, 94.4 and $95.2 \%$ after the $4^{\text {th }}$ day in case of using chitosan alone T5, T6 and T7, respectively, these reduction percent were found to be $88,91.2$ and $93.6 \%$ after the $8^{\text {th }}$ day and $80.8,92.8$ and $98.4 \%$ after the $12^{\text {th }}$ day, respectively. These results indicated that the chitosan was better than CMC as an edible coating either alone or after adding either ferulic acid or silver nanoparticles.

This result is in agreement with those obtained by Wen-Ru, et al. (2010) who found that using of silver nanoparticles delayed the growth of E.coli. They also found that the activity of respiratory chain dehydrogenase of E.coli could be whibited by silver nanoparticles.

\section{Detection of Staphylococcus spp.:}

Regarding Staphylococcus spp. Results at zero time for all treatments and content gave positive detection while all treatments gave not detectable results after 4, 8 and 12 days of refrigeration. This means that examined meat samples were free of Staphylococcus spp. During all examined periods as shown in Tab.4.

Tab. 4. Effect of treated CMC and Chitosan edible coatings with or without ferulic acid or nanosilver particles on staphylococcus spp. on some refrigerated beef sample:

\begin{tabular}{lcccc}
\hline $\begin{array}{l}\text { Refrigeration } \\
\text { period (day) }\end{array}$ & $\mathbf{0}$ & $\mathbf{4}$ & $\mathbf{8}$ & $\mathbf{1 2}$ \\
Treatment (T) & & & & - \\
\hline T1 & + & - & - & - \\
T2 & + & - & - & - \\
T3 & + & - & - & - \\
T4 & + & - & - & - \\
T5 & + & - & - & - \\
T6 & + & - & - & - \\
T7 & + & - & - & - \\
\hline T1 & & &
\end{tabular}

T1 - T7 see Tab. 1

Irais et al. (2014) reported that red meat involved in outbreak due to the presence of staphylococcus spp.

Detection of Mold and Yeast:

Regarding , using of CMC as an edible coating showed removing of molds and yeasts count and decreased from $106 \mathrm{cfu} \times 10^{3} / \mathrm{g}$ of uncoated sample to $102 \mathrm{cfu} \times 10^{3}$ 
$/ g$ after 4 days of refrigeration. These decreases were observed more with addition of either ferulic acid or silver nanoparticles. In case of ferulic acid (T3), the decreasing percent, were $46.89,55.36$ and $91.52 \%$ after 4,8 and 12 days, respectively. These values were found to be 61.01 , $59.88 \%$ and N.D when using silver nanoparticles with CMC (T4) as shown in Tab. 5.

Tab. 5. Effect of treated CMC and Chitosan edible coatings with or without ferulic acid or nanosilver particles on mold and yeast on some refrigerated beef sample:

\begin{tabular}{lcccc}
\hline & \multicolumn{3}{c}{ Mold \& Yeast cfu $\times \mathbf{1 0}^{\mathbf{3}} / \mathbf{g}$ examined } \\
sample \\
$\begin{array}{l}\text { Refrigeration } \\
\text { period (day) }\end{array}$ & $\mathbf{0}$ & $\mathbf{4}$ & $\mathbf{8}$ & $\mathbf{1 2}$ \\
Treatment (T) & & & & \\
\hline T1 & 177 & 106 & 113 & 31 \\
T2 & 177 & 102 & 98 & 17 \\
T3 & 177 & 94 & 79 & 15 \\
T4 & 177 & 69 & 71 & N.D \\
T5 & 177 & N.D & 64 & N.D \\
T6 & 177 & N.D & 25 & N.D \\
T7 & 177 & N.D & 19 & N.D \\
\hline T1- T7 see Tab.1 & & & &
\end{tabular}

Using chitosan either alone or with addition of ferulic acid or silver nanoparticles, were the superior of this edible coating than CMC. Not detectable results were found after 4 and 12 days of refrigeration. After 8 days of refrigeration, the count of mold and yeasts decreased from $177 \mathrm{cfu} \times 10^{3} / \mathrm{g}$ to $25 \mathrm{cfu} \times 10^{3} / \mathrm{g}$ and from 177 to $19 \mathrm{cfu} \times 10^{3} / \mathrm{g}$ of examined sample $\mathrm{T} 6$ and $\mathrm{T} 7$, respectively. While T5 decreased from $177 \mathrm{cfu}$ $\times 10^{3} / \mathrm{g}$ to $64 \mathrm{cfu} \times 10^{3} / \mathrm{g}$.

Again, this means that the chitosan was more efficient than CMC in molds and yeasts removing either alone or with addition of ferulic acid or silver nanoparticles.

Detection of psycrophilic bacteria:

Psycrophilic bacteria, were not detected in all treatments except T3 after 8 days of refrigeration giving $10 \mathrm{cfu} \times 10^{3} / \mathrm{g}$ of examined samples. The treatment of T6 of using chitosan with ferulic acid recorded $18 \mathrm{cfu}$ $\times 10^{3} / \mathrm{g}$ of examined samples. When using silver nanoparticles with chitosan after 8 days gave $3 \mathrm{cfu} \times 10^{3}$ $/ \mathrm{g}$ of examined samples. Silver nanoparticles was more sufficient in psycrophilic bacteria than ferulic acid with CMC and chitosan as shown in Tab. 6.

Tab. 6. Effect of treated CMC and Chitosan edible coatings with or without ferulic acid or nanosilver particles on psychrophilic bacteria on some refrigerated beef sample:

\begin{tabular}{lcccc}
\hline & \multicolumn{4}{c}{$\begin{array}{c}\text { Psychrophilic bacteria } \mathbf{c f u} \times \mathbf{1 0}^{\mathbf{3}} / \mathbf{g} \\
\text { examined sample }\end{array}$} \\
$\begin{array}{l}\text { Refrigeration } \\
\text { period (day) } \\
\text { Treatment (T) }\end{array}$ & $\mathbf{0}$ & $\mathbf{4}$ & $\mathbf{8}$ & $\mathbf{1 2}$ \\
T1 & & & & \\
T2 & N.D & N.D & N.D & N.D \\
T3 & N.D & N.D & N.D & N.D \\
T4 & N.D & N.D & 10 & N.D \\
T5 & N.D & N.D & N.D & N.D \\
T6 & N.D & N.D & N.D & N.D \\
T7 & N.D & N.D & 18 & N.D \\
\hline T1-T7 see Tab.1 & N.D & N.D & 3 & N.D \\
\hline
\end{tabular}

\section{Detection of Salmonella and Shigella:}

Examining Salmonella spp. and Shigella spp. in examined meat samples showing that control sample (T1) showed positive detection after 8 days of refrigeration while not detectable results were found with 0.0, 4 and 12 day. In case of using CMC with silver nanoparticles, results showed positive detection after 4 days of refrigeration while the rest of all treatments gave not detectable results. This means that the examined meat samples were free of both Salmonella spp. and Shigella spp. as shown in Tab.7.

Tab.7. Effect of treated CMC and Chitosan edible coatings with or without ferulic acid or nanosilver particles on salmonella and shigella on some refrigerated beef sample:

Salmonella and shigella , cfu $\times 10^{3} / \mathrm{g}$ examined sample

\begin{tabular}{lcccc}
$\begin{array}{l}\text { Refrigeration } \\
\text { period (day) } \\
\text { Treatment (T) }\end{array}$ & $\mathbf{0}$ & $\mathbf{4}$ & $\mathbf{8}$ & $\mathbf{1 2}$ \\
\hline T1 & - & - & + & - \\
T2 & - & - & - & - \\
T3 & - & - & - & - \\
T4 & - & + & - & - \\
T5 & - & - & - & - \\
T6 & - & - & - & - \\
T7 & - & - & - & - \\
\hline
\end{tabular}

\section{T1-T7 see Tab.1}

Irais et al. (2014) found that red meat in frequently involved in outbreaks mainly due to the presence of salmonella spp. and listeria spp.

Finally, from obtained results, it could be concluded that chitosan either alone or with incorporated with silver nanoparticles or ferulic acid were the superior against spoilage and pathogenic microbes more than CMC alone or with the addition of ferulic acid or silver nanoparticles.

\section{REFERENCES}

Darmadji, P. and Izumimoto, M. (1994). Effect of chitosan in meat preservation 'in Meat Science 38,243-254.

Dave, D. and Ghaly, A. E. (2011). Meat spoilage mechanisms and preservation techniques: a critical review. The American Journal of Agricultural and Biological Sciences, vol. 6, 486510.

FAO (2013). Food and Agriculture Organization. Manuals of Food-Quality Control, 4, Microbiological analysis. Rome. pp. C $9-12$ and DI -33.

Franssen, L. R., and Krochta, J. M. (2003). Edible coatings containing natural antimicrobials for processed foods. InS. Roller (Ed.), Natural Antimicrobials for the Minimal Processing of Foods. Boca Raton, Florida: CRC Press.

Han, J. H. (2000). Antimicrobial food packaging. Food Technology, 54(3), 56-65. 
Ip M.; Lui S. L.; Poon V. K.; Lung I. and Burd A. (2006). 'Antimicrobial activities of silver dressings: an in vitro comparison. J. Med. Microbiol. 55:59-63.

Kim, J. S.; Kuk, E.; Yu, K. N.; Kim, J. H.; Park, S. J.; Lee, H. J.; Kim, S. H.; Park, Y. K.; Park Y. H.; Hwang, C. Y.; Kim, Y. K.; Lee, Y. S.; Jeong, D. H. and Cho, M. H.(2007). Antimicrobial effects of silver nanoparticles. Nanomedicine. 3:95-101.

Merck, (2000). Merck Microbiology Manual $11^{\text {th }}$ Edition.

Petica, A.; Gavriliu, S.; Lungu, M.; Buruntea, N. and Panzaru, C. (2008). Colloidal silver solutions with antimicrobial properties. Mater Sci. Eng., 152:22-27.

Rai, M.; Yadav, A. and Gade, A. (2009). Silver nanoparticles as a new generation of antimicrobials. Biotechnol Adv. 27:76-83.

Ruparelia, J. P.; Duttagupta, S. P.; Chatterjee, A. K. and Mukherji, SM. A. (2006). Comparative study on disinfection potential of nanosilver and nanonickel. Technical poster, Proceedings of the 9th Annual Conference of the Indian Environmental Association (Envirovision-2006), entitled "Advances in Environmental Management and Technology", Goa, India, September 21-23.

Sanches-Ortega, Irais; Garcia-Almendarez, Blanca; Santos-Lopez, Eva Maria; Amaro-Reyes, Aldo; Barboza-Corona, J. Eleazar and Regalado, C. (2014). Antimicrobial Edible Films and coatings for meat and meat products preservation. The Scientific World Journal Volume 2014, 18 pages.
Sayanjali, Sara; Ghanbarzadeh, Babak and Ghissifar, Shiva (2011). Evaluation of antimicrobial and physical properties of edible film based on carboxymethyl cellulose containing potassium sorbate on some mycotoxigenic Aspergillus species in fresh pistachios. Food Science and Technology 44, 1133-1138.

Sharifi Soltani, Mahdi; Razavilar, Vadood and Rokni, Nourdahr (2012). Study on the antimicrobial effect of nanosilver tray packaging of minced beef at refrigerator temperature. Global Veterinaria 9(3): 284-289.

Shahverdi, A. R.; Fakhimi, A.; Shahverdi, H. R. and Minaian, S. (2007). Synthesis and effect of silver nanoparticles on the antibacterial activity of different antibiotics against Staphylococcus aureus and Escherichia coli. Nanomedicine: Nanotechnology, Biology and Medicine, 3: 168171.

Soliva-Fortuny, R.; Rojas-Graii, M. A. and MartinBelloso, O. (2012). "Polysaccharide coatings "in Edible Coatings and Films To Improve Food Quality, E. Baldwin, R. Hagenmaier and J. Bai, Eds., CRC Press, Boca Raton, Fla, USA. ,pp.103- 136

Vásconez, B. Maria; Flores, K. Silvia; Campos, A. Carmen; Alvarado, Juan and Gerschenson, N. Lía (2009). Antimicrobial activity and physical properties of chitosan-tapioca starch based edible films and coatings. Food Research International (42) 762-769.

Wen-Ru Li; Xiao-Bao Xie; Qing-Shan Shi; Hai-Yan Zeng; You-Sheng Ou-Yang. and Yi-Ben Chen (2009). Antibacterial activity and mechanism of silver nanoparticles on Escherichia coli. Appl Microbial Biotechnol, 85:1115-1122.

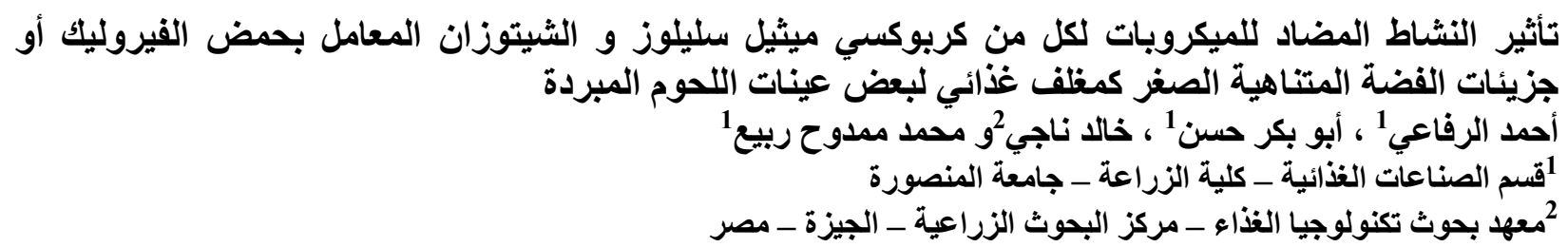

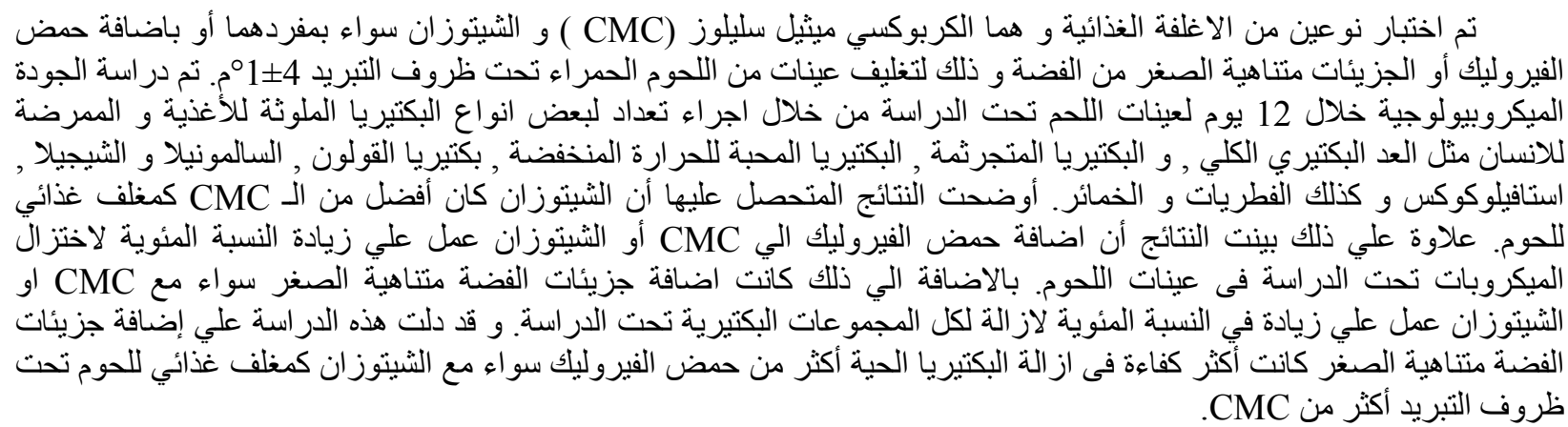

